\title{
PENGGUNAAN MOL HIJAU PADA TANAMAN KAKAO DI DESA DANGINTUKADAYA, KECAMATAN JEMBRANA, KABUPATEN JEMBRANA
}

\author{
Nuranita Naningsi \\ Program studi Teknik Industri, Fakultas Teknik, Universitas Mahendradatta \\ I.Ken Arok No.12, Peguyangan, Denpasar, Bali 80115 \\ *Email: nuranitananingsi@yahoo.co.id
}

\begin{abstract}
Abstrak - Penelitian ini bertujuan untuk mengetahui pengaruh penggunaan mol hijau untuk tanaman kakao (Theobroma cacao L) Kakao merupakan tanaman yang memiliki banyak manfaat. Produksi biji kakao sering mengalami penurunan. Salah satu faktor penyebabnya adalah serangan hama kutu putih (Planococcus minor). Serangga ini menghisap buah yang masih kecil sehingga buah akan mengering dan pertumbuhan buah terhambat. Penggunaan insektisida sintetik yang tidak tepat akan berdampak buruk. Larutan MOL (Mikroorganisme Lokal) adalah larutan hasil fermentasi yang dibuat dari bahan-bahan yang ada disekitar kita. Penelitian ini bertujuan memberikan pemahaman kepada petani tentang tujuan, manfaat dan mekanisme penggunaan mol hijau untuk mengurangi dampak penggunaan pestisida kimia. Mol hijau sangat efektif dalam mematikan kutu putih pada tanaman kakao. Penelitian ini dilaksanakan di desa dangin tukadaya Kecamatan Jembrana, kabupaten Jembrana.
\end{abstract}

Kata Kunci: Mol hijau, Kakao (Glirisidia sepium), Planococcus minor.

\begin{abstract}
This study aims to determine the effect of using green Local Microorganisms for cocoa plants ((Theobroma cacao L) Cocoa is a plant that has many benefits. Production of cocoa beans often decreases. One of the contributing factors is due to white bug infestation (Planococcus minor). These insects suck the small fruit so the fruit will dry up and fruit growth is inhibited. Inappropriate use of synthetic insecticides will have a bad impact. Local Microorganisms is fermented solution made from the materials around us. The aim of this study giving farmers an understanding of the purpose, benefits and mechanism for using green Local Microorganisms to reduce the impact of using chemical pesticides. Green Local Microorganisms is very effective in killing white lice on cocoa plants.
\end{abstract}

Keyword: Green Local Microorganisms; Glirisidia sepium; Planococcus minor.

\section{Pendahuluan \\ Kakao}

(Theobroma

cacao)

merupakan salah satu komoditas andalan perkebunan yang peranannya cukup penting bagi perekonomian nasional, khususnya menyediakan lapangan kerja, sumber pendapatan dan devisa negara. Selain itu kakao juga berperan dalam mendorong pengembangan wilayah dan pengembangan agroindustri (Maswadi, 2011). Produk kakao merupakan bahan yang sangat penting dalam beberapa jenis makanan dan minuman (Guehi et al., 2007). Berdasarkan peran dan manfaat tersebut, maka kakao mempunyai prospek yang baik untuk dikembangkan pembudidayaannya.
Salah satu penyebab turunnya produksi biji kakao adalah karena serangan hama kutu putih (Wijaya, 2007). Planococcus minor merupakan kutu putih yang hidup pada tanama kakao. Hama ini menghisap buah kakao yang masih kecil, sehingga menyebabkan pertumbuhan buah terhambat, buah mengering dan akhirnya mati (Sumarno, 2015).

Penggunaan insektisida sintetik yang tidak tepat dalam pengendalian hama menimbulkan dampak yang buruk, lebih merugikan dibanding manfaat yang dihasilkan, antara lain dapat menyebabkan timbulnya resistensi hama, munculnya hama sekunder, pencemaran lingkungan dan ditolaknya produk di pasaran dunia, 
karena masalah residu yang melebihi ambang batas toleransi.

Larutan MOL (Mikroorganisme Lokal) adalah larutan hasil fermentasi yang dibuat dari bahan-bahan yang ada disekitar kita (lokal) contohnya tanaman gamal dan tanaman hijau lainnya. Tanaman gamal dari genus Gliricidia sudah banyak diketahui manfaatnya oleh masyarakat, beberapa laporan menyebutkan bahwa ekstrak tanaman gamal memiliki aktivitas biologi antara lain sebagai anti jamur, redontisida dan insektisida nabati. Hal ini membuka peluang untuk ditemukannya senyawa kimia bahan alam yang baru dari tanaman gamal (Siregar 2010).

\section{Metode Penelitian \\ Lokasi Dan Waktu}

Daerah penelitian terletak antara $8^{0}$ 09'30"sampai $8^{0} 28^{\prime} 02^{\prime \prime}$ Lintang Selatan dan antara $114^{\circ} 25^{\prime} 53^{\prime \prime}$ sampai $114^{\circ} 5638$ " bujur timur. Desa Dangin tukadaya berada pada ketinggian 306,84 $\mathrm{m}$ dpl, dengan topografi Kabupaten Jembrana yang memiliki luas wilayah mencapai 84.180 hektar tersebut bergelombang dan berbukit di bagian utara, dan landai di bagian selatan. Rata-rata ketinggian wilayah Kabupaten Jembrana mencapai 306,84 meter di atas permukaan laut dengan titik tertinggi hanya 700 meter. Kabupaten Jembrana memiliki pantai sepanjang $78 \mathrm{~km}$ dan dilalui 37 sungai dengan panjang keseluruhan mencapai 495,8 kilometer.

Secara administrasi daerah penelitian pada batas-batas wilayah sebagai berikut: (1) Sebelah utara dengan Kabupaten Buleleng, (2) Sebelah Timur, Kabupaten Tabanan, (3) sebelah selatan, Samudra Indonesia, dan (4) sebelah barat adalah Selat Bali. Penelitian dilakukan di Desa Dangin tukadaya, Kecamatan Jembrana. Kabupaten Jembrana.

\section{Metode Penelitian Lokasi Dan Waktu}

Desa Dangin Tukadaya dengan luas wilayah $640 \mathrm{Ha}$ memiliki sumber daya alam yang dapat dikembangkan sebagai Potensi Desa untuk masyarakat setempat.Secara geografis Desa Dangin Tukadaya termasuk daerah desa dataran rendah $281 \mathrm{Ha} / \mathrm{m}^{2}$ dan desa dataran tinggi/pegunungan 359 $\mathrm{ha} / \mathrm{m}^{2}$. Luas wilayah Desa Dangin Tukadaya $640 \mathrm{Ha} / \mathrm{m}^{2}$

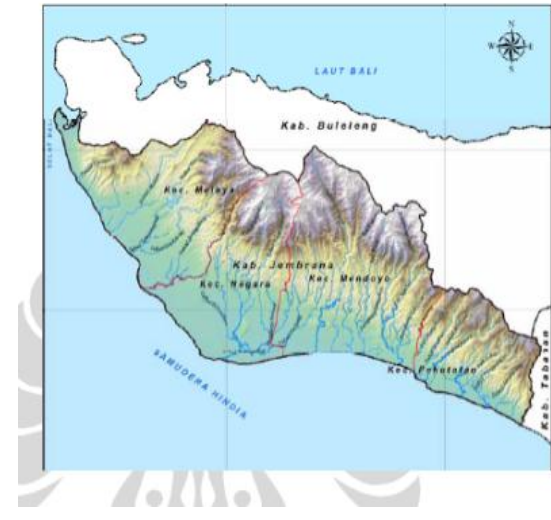

Gambar 1.

Peta Wilayah Kabupaten Jembrana Propinsi Sumber: Bappeda Kabupaten Jembrana

\subsection{Bahan dan Alat}

Bahan-bahan yang digunakan dalam penelitian ini terdiri dari: mol hijau, air dan tanaman kakao.

Alat-alat yang digunakan dalam penellitian ini, terdiri dari: daun gamal dan daun hijau lainnya,kohe, gula, tanah subur dan air kelapa,ember/drum, penutup berupa plastik, kamera, pulpen, buku dan penggaris.

\subsection{Metode Penelitian}

Metode dalam penelitian ini adalah metode sdengan cara membuat mol hijau dan ditunjang dan melakukan langkah kerja.

1. Menyediakan bahan-bahan untuk membuat pupuk yaitu: (a) bahannya berupa daun gamal dan daun hijau lainnya, kohe, gula, air bersih ; (b) kohe; (c) air bersih (bukan air yang mengadung kaporit) (d) kohe (e) gula pasir; (f) tanah/lumpur yang subur; (g) air kelapa, setelah bahan tersedia maka persiapkan alat, alatnya yaitu: (a) ember/ drum; (b) kresek plastic besar; (c) tong plastik; (d) alat pengaduk; . Hasil olahan bahan-bahan tersebut menjadi MOL. MOL digunakan sebagai bantuan dari penguraian bahan tersebut, karena pada dasarnya MOL mengandung berbagai jenis bakteri pengurai, yang berfungsi untuk menbantu penguraian atau pelapukan bahan-bahan tersebut.

2. Setelah Mol hijau jadi sekitar 5 hari, pupuk cair ini bisa dimanfaatkan.

3. Lalu melakukan aplikasi MOL hijau yang sudah disediakan aplikasi mol 
hijau dilakukan 6 bulan sebelum tanam, bisa dilakukan seminggu sekali setelah tanam, dan biasanya disemprotkan kedaun. Sebaiknya pengaplikasian mol hijau dilakukan pada sore hari, hal ini dimaksud agar pupuk yang diaplikasikan tidak memuai atau hilang karena adanya suhu lingkungan yang panas. sebaiknya dilakukan pengaplikasian mol hijau pada waktu sore hari, hal ini dimaksud agar pupuk yang diaplikasikan tidak memui atau hilang karena adanya suhu lingkungan yang panas.

4. Kemudian melakukan penyiraman dengan mengunakan air bersih umunya penyiraman dilakukan pada waktu sore hari atau pada waktu pagi hari saja.

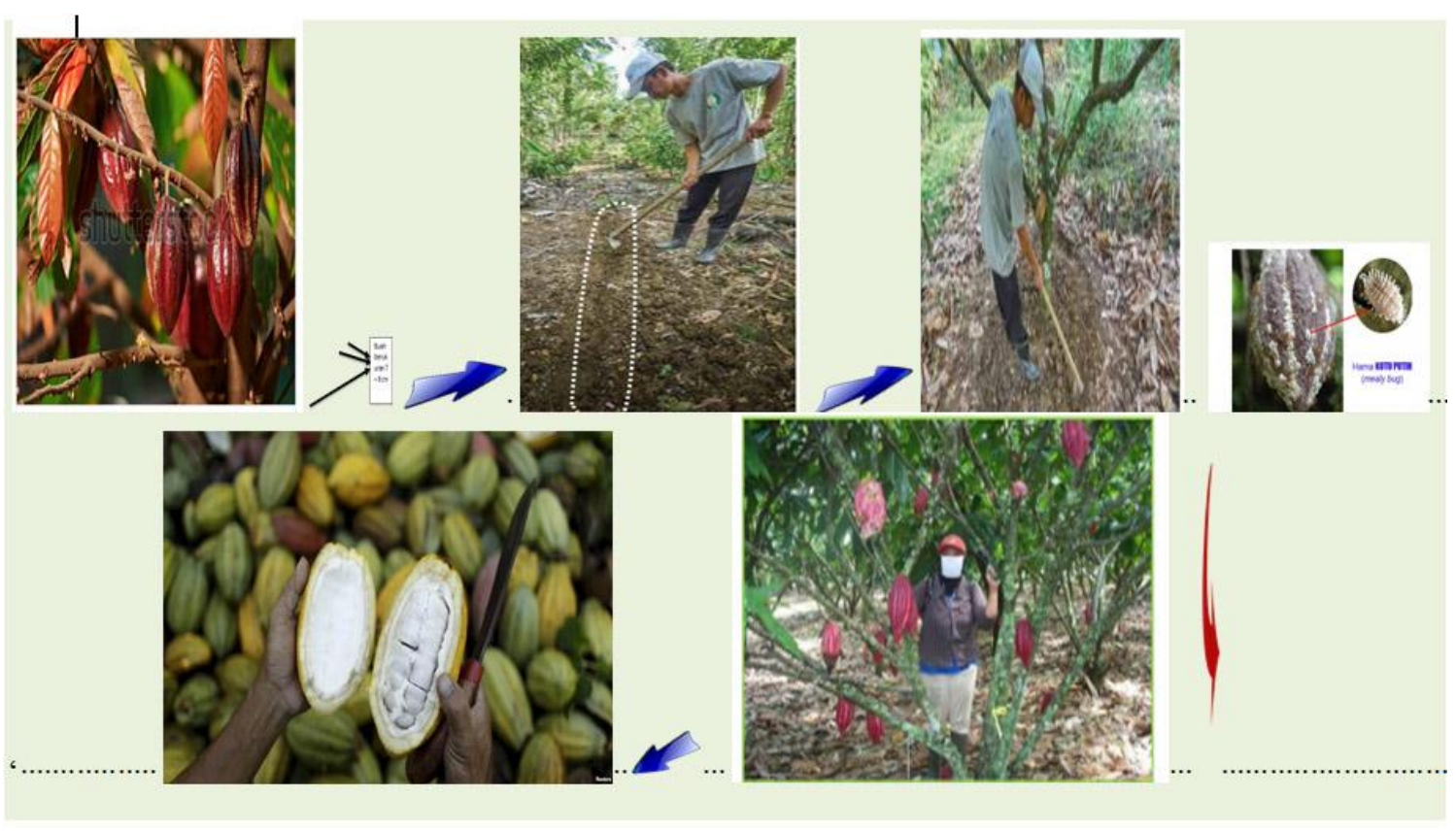

Gambar 2

Metode Pengaplikasian Mol Hijau Pada Tanaman Kakao

Berdasarkan hasil dilapangan menunjukkan bahwa pemberian mol hijau pada tanaman kakao mampu menekan hama kutu putih (Planococcus minor) namun pemberian mol hijau sama dengan pengunaan pupuk organik yang memiliki beberapa kendala seperti respon tumbuhan terhadap pupuk begitu lambat. Menurut Nugroho (2007), pengunaan pupuk organik pada dasarnya memiliki beberapa kelemahan, salah satunya diantaranya tanaman cukup lambat dalam merespon pupuk tersebut, hal ini disebabkan karena beberapa faktor diantaranya: (a) pada tahap pertama, pupuk organik akan berfokus pada perbaikan kondisi tanah yang kurang baik, seperti perbaikan sipat fisik tanah, dan sifat kimia tanah, terlebih lagi pada awalnya sejarah tanah yang digunakan bekas lahan yang digunakan berbagai jenis pestisida dan pupuk kimia yanng berlebih sehingga mikroorganisme dalam pupuk cair organik bekerja keras untuk memperbaiki sifat fisik tanah tersebut. Sifat fisik dan kimia tanah sangat berperan penting dalam pertumbuhan tanaman, karena akar berada pada media tanah, yang dimana akar merupakan inti dari kegiatan proses pencarian unsur hara bagi tanaman tersebut. Jika sifat tanah kurang baik, hal ini sangat mempengaruhi pertumbuhan tanaman dampak terberat dari hal ini tanaman akan kekurangan unsur hara, terutama unsur $\mathrm{N}$ dan unsur $\mathrm{P}$, yang merupakan unsur yang mudah hilang terutama nitrogen; (b) tahap kedua, pada tahap kedua sifat kimia dan fisik tanah sudah mulai membaik, kinerja bakteri sudah tidak terlalu berat pada seperti halnya tahap pertama, pada tahap ini tanaman sudah bisa menyerap pupuk yang ada didalam tanah, unsur hara mulai tersedia, kondisi tanah mulai membaik, dan mikroorganisme dalam tanah mulai hidup kembali dan bisa mengurai bahan bahan organik dalam tanah, hal ini sangat 
mengutungkan bagi tanaman; (c) tahap ketiga, pada tahap ini unsur hara dan sifat fisik maupun kimia dalam tanah sudah tersedia, kondisi tanah sudah membaik. Hal ini mulai bisa dirasakan pada pemupukan ketiga pada pengunaan pupuk organik, salah satunya pupuk cair organik.

Hasil penelitian menunjukkan bahwa pemberian mol hijau pada sangat berpengaruh pada pertumbuhan vegetatif tanaman yang dimana bagain vegetatif ini sangat berperan dalam proses pertumbuhan tanaman seperti akar batang dan daun. Pemberian mol hijau memicu tumbuhnya daun yang lebih banyak, mampu memperbaiki sifat fisik tanah, dan kimia tanah yang merupakan faktor penentu dalam pertumbuhan tanaman kakao, pada dasarnya pemberian pupuk mol hijau mengadung unsur hara $P$ akan mempercepat pertumbuhan daun karna pada dasarnya kapur/kalsium banyak terletak pada daun tanaman itu sendiri sehingga pemberian dosis yang tepat akan membuat daun bertambah dengan normal.

Pemberian mol hijau dengan cara menyemprotkan kedaun tanaman kakao mampu membunuh hama kutu putih (Planococcus minor). Mol hijau ini sangat efektif digunakan sebagai insektisida nabati yang murah, aman, mudah dibuat dan ramah lingkungan. Penyemprotan dengan menggunakan mol hijau mampu membunuh hama kutu putih pada tanaman kakao

\section{KESIMPULAN DAN SARAN \\ 4.1 Kesimpulan}

Berdasarkan hasil penelitian di Desa Dangin tukadaya, Kecamatan Jembrana. Kabupaten Jembrana maka di peroleh beberapa kesimpulan sebagai berikut:

1. Pengunaan mol hijau memiliki daya insektisida terhadap kutu putih (Planococcus minor) pada tanaman kakao (Theobroma cacao).
2. Pengenalan pestisida nabati menggunakan mol hijau sangat penting guna melindungi tanaman kakao dari pestisida kimia terus menerus, serta dapat meningkatkan kualitas dan mutu dari tanaman kakao, sehingga mampu menghasilkan produk yang aman, lingkungan juga tidak tercemar.

3. Pengunaan mol hijau mampu membasmi hama kutu putih (Planococcus minor) dan sebagai fungisida pada tanaman kakao.

\subsection{Saran}

1. Pada daerah penelitian diharapkan petani mampu memahami bagaimana cara menggunakan pestisida nabati mol karena mol hijau memiliki daya insektisida terhadap hama kutu (Planococcus minor) pada tanaman (Theobroma cacao).

\section{DAFTAR PUSTAKA}

Maswadi. 2011. Agribisnis Kakao dan Produk Olahannya Berkaitan dengan Kebijakatan Tarif Pajak di Indonesia. J. Perkebunan \& Lahan Tropika. 1: 23-30.

Pracaya, 2007.. "Hama dan Penyakit Tanaman.". Jakarta: Penebar Swadaya. Badan Pusat Statistik, Kabupaten Bangli 2001.Bangli dalam angka tidak dipublikasikan.

Siregar, Tumpal. 2004."Cokelat". Jakarta: Penebar Swadaya.

Sumarno, E. 2015. "Jenis-Jenis Serangga Hama Berdasarkan Tingkat Kerusakan Yang Ditimbulkan. Universitas Halu Oleo. Kendari.

Wijaya,S.Y. 2007. "Kolonisasi Semut Hitam (Dolichoderus thoracicus smith) pada tanaman Kakao (Theobroma cacao L.) Dengan Pemberian Pakan Alternatif. (Skripsi). Universitas Sebelas Maret. Surakarta. 